\title{
SIFAT PELENGKUNGAN LIMA JENIS KAYU DENGAN DUA MACAM PERLAKUAN AWAL
}

\author{
(Bending Characteristics of Five Wood Species With Two Types of \\ Pretreatment)
}

Oleh/By :

Achmad Supriadi $^{1)}$ \& Osly Rachman ${ }^{1)}$

\begin{abstract}
Secondary wood industry, i.e. furniture, appliance of sport and boat commonly used wood component in curved forms. Such square components were mostly worked out by sawing boards with a racksaw. This traditional method resulted in low recovery of bending works. In many cases, the curved components could be prepared by bending pieces of pre-treated boards using certain jigs as required in the final work. This study examined bending characteristics of 5 wood species, i.e. asam jawa (Tamarindus indica L.), kendal (Eretia acuminata R.Br.), balobo (Diplodiscus sp.), marasi (Hymenaea sp.) and rasamala (Altingia excelsa N.). Samples were priorly treated with 2 kinds of pretreatment, i.e. (1) steaming and (2) immersing in 3\% NaOH solution followed by steaming. Results showed that samples with steaming treatment could be bent at radius of $51 \mathrm{~cm}$, while the second treatment could be bent up to radius of $26 \mathrm{~cm}$. The effectiveness of pre-treatments were significantly affected by woood species. Asam jawa possessed better bending characteristics than other wood species.
\end{abstract}

Keywords : Bending, steaming, immersing, density, swelling.

\begin{abstract}
ABSTRAK
Industri kayu sekunder cukup banyak menggunakan komponen kayu dalam bentuk lengkung seperti industri mebel, alat-alat olah raga dan perahu. Komponen dalam bentuk lengkungan tersebut umumnya dibentuk dengan cara digergaji mengikuti pola lengkungan. Cara pembuatan komponen lengkung dengan menggunakan gergaji cenderung menghasilkan rendemen yang rendah. Cara lain yang lebih efisien adalah pelengkungan kayu secara fisis dan kimia.

Dalam studi ini dilakukan determinasi karakteristik pelengkungan pada 5 jenis kayu, yaitu kayu asam jawa (Tamarindus indica L.), kendal (Eretia acuminata R.Br.) balobo (Diplodiscus sp.), marasi (Hymenaea sp.) dan rasamala (Altingia excelsa $\mathrm{N}$.) dengan dua macam perlakuan awal yaitu (1) pengukusan dan (2) perendaman dalam larutan $\mathrm{NaOH}$ 3\% dilanjutkan dengan pengukusan. Hasil penelitian menunjukkan bahwa kayu yang terlebih dahulu direndam dalam larutan $\mathrm{NaOH} 3 \%$ selama 7 hari kemudian dikukus, dapat dilengkungkan hingga radius $26 \mathrm{~cm}$, sedangkan kayu yang diberi pengukusan hanya dapat dilengkungkan hingga radius $51 \mathrm{~cm}$. Kayu asam jawa memiliki karakteristik pelengkungan yang lebih baik dibandingkan dengan kayu marasi, balobo, kendal dan rasamala.
\end{abstract}

Kata kunci : Pelengkungan, pengukusan, perendaman, kerapatan, pengembangan dimensi.

1) Peneliti pada Pusat Penelitian dan Pengembangan Hasil Hutan, Bogor 


\section{PENDAHULUAN}

Industri pengolahan kayu sekunder di Indonesia cukup banyak yang menggunakan komponen kayu dalam bentuk lengkung, seperti rangka sandaran kursi, lengan kursi, tempat tidur, alat-alat olah raga, rangka perahu dan lain-lain. Komponen dalam bentuk lengkung tersebut sampai saat ini masih banyak dibentuk dengan cara digergaji. Cara ini memiliki beberapa kelemahan seperti terjadinya limbah yang cukup tinggi, mengurangi kekuatan dan keindahan orientasi serat kayu (Kollman and Cote, 1968). Cara lain yang lebih efisien adalah pelengkungan sortimen kayu secara mekanis dengan diawali perlakuan fisis atau kimia, atau kombinasi keduanya.

Di negara-negara Eropa dan Amerika Serikat, pelengkungan kayu telah lama dipraktikkan secara mekanis dengan praperlakuan plastisasi dengan panas (api langsung, perebusan, pengukusan) dan penggunaan bahan kimia seperti urea, dimethylol urea, dimethyl sulfoxide (DMSO) dan amoniak cair. (Anonim, 1999). Di Indonesia, penelitian pelengkungan kayu telah dilakukan oleh Supriadi dan Rachman (2002) pada kayu tusam yang disadap maupun yang tidak disadap yang terlebih dahulu diberi praperlakuan perebusan dan praperlakuan perendaman dalam larutan urea 5\%. Hasil penelitian menunjukkan kedua praperlakuan tersebut mampu meningkatkan titik kritis radius lengkung. Penelitian pelengkungan kayu lainnya dilakukan oleh Malik dan Krisdianto (2003). Hasil penelitian menunjukkan bahwa kayu mangium yang diberi gas ammonia dapat dilengkungkan pada radius $200 \mathrm{~mm}$ tanpa mengalami cacat pelengkungan.

Penggunaan larutan $\mathrm{NaOH}$ sebelum kayu dilengkungkan dapat menjadikan kayu lebih mudah dilengkungkan (Fengel and Wegener, 1984). Pada penelitian ini dilakukan pelengkungan kayu dengan menggunakan praperlakuan pengukusan dan penggunaan bahan kimia $(\mathrm{NaOH})$ pada 5 jenis kayu, yaitu kayu asam jawa (Tamarindus indica L.), kendal (Eretia acuminata R.Br.), balobo (Diplodiscus sp.), marasi (Hymenaea sp.) dan rasamala (Altingia excelsa N.)

\section{METODE PENELITIAN}

\section{A. Bahan dan Alat}

Penelitian ini menggunakan 5 jenis kayu yaitu kayu asam jawa (Tamarindus indica L.), kendal (Eretia acuminata R.Br.), balobo (Diplodiscus sp.), marasi (Hymenaea sp.) dan rasamala (Altingia excelsa N.). Alat bantu yang digunakan adalah alat pengukus (steam), bak perendam dengan ukuran 40 × 50 × $15 \mathrm{~cm}$, mal pelengkung dan klem- F (Gambar 1), labu erlenmeyer, penjepit, oven, penggaris, kaliper, timbangan, lup, plastik dan alat tulis. 


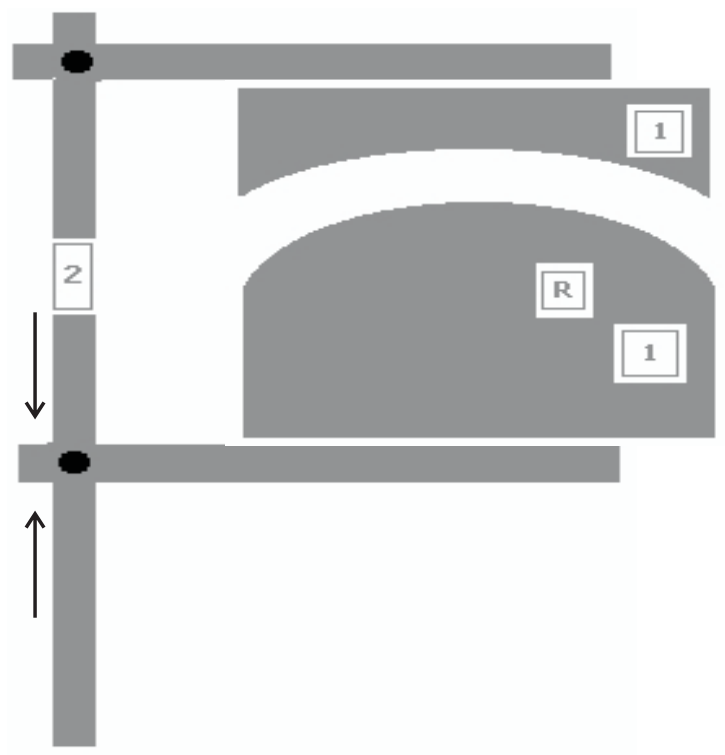

Keterangan (Remark):

1 = Mal pelengkung (Bending jig)

$2=$ Klem $-\mathrm{F}($ F clamp)

$\mathrm{R}=$ Radius lengkung (Bending radius)

Gambar 1. Mal pelengkung dan klem-F

Figure 1. Bending jig and F-clamp

\section{B. Metode}

\section{Pembuatan contoh uji}

Untuk contoh uji dipilih kayu bebas cacat dalam kondisi kering udara dengan ukuran 2,5 cm (lebar) x $1 \mathrm{~cm}$ (tebal) x 32,5 cm (panjang) masing-masing 160 buah untuk setiap jenis kayu. Contoh uji kemudian dipotong menjadi dua bagian, bagian pertama ukuran $2,5 \mathrm{~cm}$ (lebar) x 1 $\mathrm{cm}$ (tebal) x 2,5 cm (panjang) untuk contoh uji sifat fisis dan bagian kedua ukuran 2,5 cm (lebar) x 1 (tebal) x $30 \mathrm{~cm}$ (panjang) untuk contoh uji pelengkungan. Banyaknya contoh uji pelengkungan untuk masing-masing perlakuan adalah 80 buah untuk setiap jenis kayu, dengan rincian 20 buah disediakan untuk uji pelengkungan; 60 buah untuk 3 kali ulangan uji pelengkungan pada radius yang telah diperoleh dari hasil uji pendahuluan (setiap ulangan diuji 20 buah). Contoh uji pelengkungan sebelum dilengkungkan terlebih dahulu diberi 2 macam perlakuan awal, yaitu : (1) dikukus selama 30 menit dan (2) direndam dalam larutan Natrium Hidroksida $(\mathrm{NaOH})$ konsentrasi 3\% selama 7 × 24 jam dilanjutkan dengan pengukusan selama 30 menit. Pengukusan (steaming) dilakukan selama 30 menit dengan menggunakan alat pengukusan berukuran diameter $35 \mathrm{~cm}$ dan tinggi $60 \mathrm{~cm}$. Setelah perendaman dan pengukusan, dilakukan pelengkungan dengan menggunakan mal pelengkung (Gambar 1). 


\section{Pengujian}

a. Sifat fisis kayu

1) Kerapatan

Pengukuran kerapatan dilakukan dengan menggunakan contoh uji ukuran $1 \mathrm{~cm}$ (tebal) $\mathrm{x}$ $2,5 \mathrm{~cm}$ (lebar) x 2,5 cm (panjang). Diukur berat kering oven dan volume kering oven. Kerapatan ditentukan berdasarkan rumus berikut:

$$
\text { Kerapatan }=\frac{\text { Berat kering oven }(\text { gram })}{\text { Volume kering oven }\left(\mathrm{cm}^{3}\right)}
$$

2) Pengembangan dimensi

Contoh uji yang digunakan dalam penentuan pengembangan dimensi berukuran $1 \mathrm{~cm}$ (tebal) x 2,5 cm (lebar) x 2,5 cm (panjang). Contoh uji direndam selama 7 x 24 jam dalam larutan $\mathrm{NaOH} 3 \%$ bersamaan dengan contoh uji pelengkungan. Setelah perendaman, contoh uji diukur kembali dimensinya. Pengembangan volume dihitung dengan rumus sebagai berikut:

$$
\text { Pengembangan volume }(\%)=\frac{\text { Volume akhir }\left(\mathrm{m}^{3}\right)-\text { Volume awal }\left(\mathrm{m}^{3}\right)}{\text { Volume awal }\left(\mathrm{m}^{3}\right)} \times 100 \%
$$

\section{b. Pelengkungan kayu}

Semua contoh uji dalam keadaan masih panas dan basah kemudian dilengkungkan satu per satu pada mal dan dikunci selama 5 menit hingga berbentuk melengkung mengikuti bentuk mal. Radius lengkung yang dipakai pada penelitian ini adalah 80, 60, 55, 50, 45, 40, 35, 30, 25, 20, 17 dan $14 \mathrm{~cm}$. Contoh uji dilengkungkan secara bertahap, dimulai pada radius terbesar, apabila tidak terjadi kerusakan maka contoh uji yang sama dilengkungkan pada radius yang setingkat lebih rendah dan demikian seterusnya. Apabila terjadi kerusakan berupa patah, retak atau pecah pada contoh uji, maka contoh uji tersebut diasumsikan mampu dilengkungkan pada satu kelas lebih tinggi dari kelas radius dimana terjadi kerusakan pada contoh uji. Nilai lengkung diperoleh apabila contoh uji yang rusak $5 \%$ dari jumlah contoh uji yang dilengkungkan pada radius tersebut. Percobaan ini diulang sebanyak tiga kali.

Setelah dilakukan proses pelengkungan, contoh uji tersebut ditentukan kemampuan lengkungnya berdasarkan klasifikasi kualitas pelengkungan seperti disajikan pada Tabel 1. 
Tabel 1. Klasifikasi kualitas pelengkungan kayu Table 1. Classification of wood bending quality

\begin{tabular}{|c|l|}
\hline $\begin{array}{c}\text { Radius kelengkungan } \\
\text { (Bending radius), cm }\end{array}$ & \multicolumn{1}{c|}{$\begin{array}{c}\text { Kualitas pelengkungan } \\
\text { (Bending quality) }\end{array}$} \\
\hline$\leq 15$ & Baik Sekali (Very good) \\
$16-24$ & Baik (Good) \\
$25-33$ & Sedang (Fair) \\
$34-42$ & Jelek (Poor) \\
$>42$ & Jelek Sekali (Very poor) \\
\hline
\end{tabular}

Sumber (Source) : Rachman dan Saeful (2001)

\section{Analisis Data}

Data hasil pengamatan masing-masing pengujian sifat kayu (kerapatan, pengembangan dimensi dan radius lengkung) dibuat tabulasinya, kemudian dihitung rata-ratanya. Dari nilai rata-rata radius lengkung, ditetapkan kelas lengkung masing-masing jenis kayu.

Untuk mengetahui pengaruh perlakuan awal dan jenis kayu terhadap kemampuan lengkung dilakukan uji sidik ragam. Bila berpengaruh nyata, pengujian dilanjutkan dengan uji Beda Nyata Terkecil (BNT). Untuk mengetahui hubungan antara sifat fisik kayu (kerapatan dan pengembangan dimensi) dengan kemampuan lengkung, dilakukan uji regresi sederhana. Pengolahan data dilakukan dengan bantuan program Microsta (Mustafa, 1990).

\section{HASIL DAN PEMBAHASAN}

\section{A. Sifat Fisis Kayu}

Data hasil pengamatan sifat fisis kayu yang meliputi kerapatan dan pengembangan dimensi disajikan pada Tabel 2. Kayu asam jawa memiliki kerapatan tertinggi, sedangkan kayu balobo memiliki kerapatan terendah dibandingkan jenis kayu lainnya. Demikian pula hasil pengukuran pengembangan dimensi menunjukkan kayu asam jawa mengalami pengembangan dimensi tertinggi dan kayu balobo terendah. Terdapat kecenderungan makin tinggi kerapatan suatu jenis kayu, makin tinggi pula terjadinya pengembangan dimensi pada kayu tersebut

Perendaman kayu dalam larutan $\mathrm{NaOH} 3 \%$ telah mengakibatkan terjadinya pengembangan pada kelima jenis kayu sekitar 5,2\% sampai 10,7\%. Dibandingkan dengan pengembangan dengan air atau uap air yang berkisar antara 2\%-3\%, maka nilai tersebut jelas lebih tinggi. Pengembangan dimensi kayu menunjukkan bahwa larutan $\mathrm{NaOH}$ tersebut telah mampu menghidrolisa kayu sehingga terjadi degradasi atau pemekaran selulosa dalam dinding sel kayu. Pemekaran ini mengakibatkan kayu menjadi lunak (plastis) sehingga lebih mudah dilengkungkan (Fengel and Wegener, 1984). 
Tabel 2. Kerapatan, pengembangan dimensi dan radius lengkung 5 jenis kayu Table 2. Density, swelling and bending radius of 5 wood species

\begin{tabular}{|c|l|c|c|c|}
\hline No. & \multicolumn{1}{|c|}{$\begin{array}{c}\text { Jenis kayu } \\
\text { (Wood species) }\end{array}$} & $\begin{array}{c}\text { Kerapatan } \\
\text { (Density) }\end{array}$ & $\begin{array}{c}\text { Pengembangan } \\
\text { dimensi (Swelling), \% }\end{array}$ & $\begin{array}{c}\text { Radius lengkung } \\
\text { (Bending radius) }\end{array}$ \\
\hline 1 & Asam jawa & 0,83 & 10,7 & 22,8 \\
2 & Kendal & 0,55 & 6,7 & 45 \\
3 & Balobo & 0,66 & 5,2 & 37,5 \\
4 & Marasi & 0,89 & 7,3 & 30 \\
5 & Rasamala & 0,73 & 5,5 & 58,4 \\
\hline & Rata-rata (Average) & 0,73 & 7,0 & 39,2 \\
\hline
\end{tabular}

\section{B. Kualitas Pelengkungan}

Rekapitulasi rata-rata radius lengkung dan klasifikasi kualitas pelengkungan kayu disajikan pada Tabel 3. Hasil uji pelengkungan menunjukkan kayu asam jawa yang paling mudah dilengkungkan, yaitu mampu dilengkungkan sampai radius $25 \mathrm{~cm}$ pada kayu yang telah mengalami pengukusan dan 20,6 cm pada kayu yang telah direndam larutan $\mathrm{NaOH} 3 \%$ yang dilanjutkan dengan pengukusan. Kayu marasi cukup mudah dilengkungkan, sedangkan kayu balobo, rasamala dan kendal sulit untuk dilengkungkan. Berdasarkan kualitas lengkungan, hanya kayu asam jawa yang memiliki kualitas baik

Radius lengkung pada kelima jenis kayu yang diteliti ini masih lebih besar dibandingkan dengan yang diperoleh pada kayu tusam. Kayu tusam yang diberi perlakuan awal berupa perendaman dengan air selama 24 jam kemudian direbus selama 1/2 jam mampu dilengkungkan secara baik sampai radius $25 \mathrm{~cm}$ (Supriadi dan Rachman, 2002). Artinya kelima jenis kayu dengan perlakuan pengukusan (Tabel 3 kolom A) berada pada kelas kualitas pelengkungan di bawah kayu tusam yang diberi perlakuan awal perebusan. Hal ini diduga karena kayu tusam (soft wood) memiliki struktur yang dominan terdiri dari trakeida (85-95\%). Jaringan ini memiliki dimensi lebih panjang, sehingga secara mekanis memiliki elastisitas lebih tinggi (Bodig and Jayne, 1982). 
Tabel 3. Radius lengkung dan kualitas pelengkungan 5 jenis kayu Table 3. Bending radius and bending quality of 5 wood species

\begin{tabular}{|c|l|c|c|c|l|}
\hline \multirow{2}{*}{ No } & \multirow{2}{*}{$\begin{array}{c}\text { Jenis kayu } \\
\text { (Wood species) }\end{array}$} & \multicolumn{3}{|c|}{$\begin{array}{c}\text { Radius lengkung } \\
\text { (Bending radius), cm }\end{array}$} & \multirow{2}{*}{$\begin{array}{c}\text { Kelas kualitas } \\
\text { (Quality class) }\end{array}$} \\
\cline { 3 - 5 } & $\mathrm{A}$ & $\mathrm{B}$ & $\begin{array}{c}\text { Rata-rata } \\
\text { (Average) }\end{array}$ & \\
\hline 1 & Asam jawa & 25 & 20,6 & 22,8 & Baik (Very good) \\
2 & Kendal & 65 & 25 & 45 & Jelek sekali (Very poor) \\
3 & Balobo & 50 & 25 & 37,5 & Jelek (Poor) \\
4 & Marasi & 35 & 25 & 30 & Sedang (Fair) \\
5 & Rasamala & 80 & 36,7 & 58,4 & Jelek sekali (Very poor) \\
\hline
\end{tabular}

Keterangan (Remarks) : A = Perlakuan awal pengukusan (Steamingpretreatment); $\mathrm{B}=$ Perlakuan awal perendaman dalam larutan $\mathrm{NaOH} 3 \%$ dan pengukusan (Soaking pretreatment in $3 \% \mathrm{NaOH}$ solution and steaming)

\section{Pengaruh Praperlakuan dan Jenis Kayu Terhadap Radius Lengkung}

Pada Tabel 3 terlihat bahwa contoh uji yang terlebih dahulu direndam dalam larutan $\mathrm{NaOH} 3 \%$ mampu mencapai radius lengkung rata-rata $26,8 \mathrm{~cm}$, sedangkan yang diberi perlakuan pengukusan hanya mampu dilengkungkan pada radius $51,7 \mathrm{~cm}$. Secara statistik perlakuan awal memberikan pengaruh sangat nyata terhadap radius lengkung (Lampiran 1A). $\mathrm{Hal}$ ini menunjukkan bahwa kayu yang telah melalui perendaman larutan $\mathrm{NaOH}$ menjadi lebih mudah dilengkungkan dibandingkan dengan yang tidak direndam. Hal ini mungkin disebabkan oleh larutan bahan kimia yang bersifat basa mampu menghidrolisa kayu, sehingga terjadi degradasi atau pemekaran selulosa dalam dinding sel kayu (Fengel and Wegener, 1984). Pemekaran ini mengakibatkan kayu menjadi lunak (plastis) sehingga lebih mudah dilengkungkan (Fengel and Wegener, 1984). Hasil ini sama dengan hasil penelitian pelengkungan sebelumnya pada kayu tusam, dimana perlakuan awal yang diberikan berpengaruh sangat nyata terhadap kualitas pelengkungan (Supriadi dan Rachman, 2002).

Dilihat pada jenis kayunya, kayu asam jawa dapat dilengkungkan rata-rata pada radius lengkung 22,8 cm, kemudian menurun berturut-turut pada kayu marasi, balobo, kendal dan rasamala. Secara statistik jenis kayu memberikan pengaruh nyata terhadap radius lengkung (Lampiran 1A). Hal ini menunjukkan bahwa kayu asam jawa lebih mudah dilengkungkan dibandingkan keempat jenis kayu lainnya. Hasil uji lanjutan (BNT) menunjukkan tidak ada perbedaan nyata radius lengkung antara jenis kayu, kecuali antara kayu rasamala dengan keempat jenis kayu lainnya (Lampiran 1B).

\section{Hubungan Sifat Fisis Kayu dengan Radius Lengkung}

Pasangan data sifat fisis kayu yang meliputi kerapatan dan pengembangan dimensi dengan radius pelengkungan disajikan pada Tabel 2. Kayu asam jawa memiliki kerapatan 
tertinggi, juga mengalami pengembangan dimensi (volumetris) tertinggi dan yang paling mudah dilengkungkan dibandingkan jenis kayu lainnya. Diduga ada keterkaitan antara nilai kerapatan suatu jenis kayu dengan mudah tidaknya kayu tersebut dilengkungkan. Juga diduga ada keterkaitan antara pengembangan dimensi suatu jenis kayu dengan mudah tidaknya kayu tersebut dilengkungkan. Untuk menguji keterkaitan dan kecenderungan yang terjadi, dilakukan analisis regresi linier masing-masing antara nilai kerapatan dengan radius lengkung dan antara pengembangan dimensi dengan radius lengkung.

Hasil analisis menunjukkan kelemahan hubungan nyata antara pasangan data radius lengkung dengan kerapatan (Lampiran 1A). Persamaan regresinya adalah Y $=88,0466+$ $67,8623 \mathrm{X}$, dengan nilai koefisien determinasi $\left(R^{2}\right)=0,25$. Nilai $R^{2}$ tersebut menunjukkan keterbatasan hubungan antara radius lengkung dengan kerapatan kayu.

Hubungan antara pengembangan dimensi dengan radius lengkung menunjukkan adanya kaitan yang sangat nyata pada tingkat kepercayaan 99\% (1\%) seperti pada Gambar 2. Persamaan regresinya adalah $\mathrm{Y}=57,1963-2,6213 \mathrm{X}$ dengan nilai $\mathrm{R}^{2}=0,26$. Persamaan regresi tersebut menunjukkan lereng (slope) negatif, artinya makin tinggi nilai pengembangan dimensi, makin kecil radius lengkungnya, makin mudah kayu tersebut untuk dilengkungkan. Nilai $\mathrm{R}^{2}$ tersebut menunjukkan bahwa $26 \%$ variabel radius lengkung dapat dijelaskan oleh variabel pengembangan dimensi. Hasil uji sidik ragam dan uji lanjutan Beda Nyata Terkecil (BNT) masing-masing disajikan pada Lampiran 1A dan 1B.

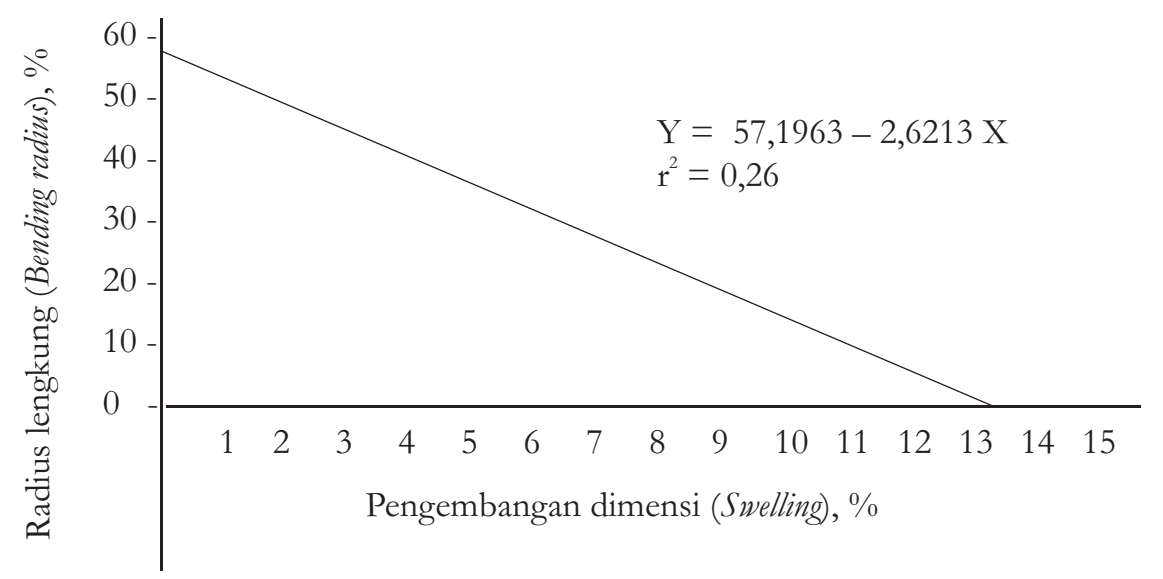

Gambar 2. Hubungan antara radius lengkung dengan pengembangan dimensi kayu Figure 2. Relationship between swelling and bending radius 


\section{KESIMPULAN DAN SARAN}

\section{A. Kesimpulan}

1. Hasil pelengkungan 5 jenis kayu yang telah diberi praperlakuan perendaman dengan larutan $\mathrm{NaOH} 3 \%$ menunjukkan bahwa kayu asam jawa termasuk baik, kayu marasi sedang, kayu balobo jelek, kayu kendal dan rasamala sangat jelek.

2. Praperlakuan sebelum kayu dilengkungkan dan jenis kayu berpengaruh nyata terhadap radius pelengkungan. Kayu yang diberi perlakuan awal perendaman dengan larutan $\mathrm{NaOH} 3 \%$ lebih mudah dilengkungkan dibandingkan dengan yang tidak direndam. Tidak ada perbedaan nyata radius pelengkungan antara kelima jenis kayu, kecuali antara kayu rasamala dengan keempat jenis kayu lainnya.

3. Analisis regresi antara sifat fisis kayu dengan radius pelengkungan menunjukkan tidak ada hubungan nyata antara kerapatan kayu dengan radius lengkung, sedangkan antara radius lengkung dengan pengembangan dimensi kayu menunjukkan hubungan yang sangat nyata dengan persamaan $\mathrm{Y}=57,1963-2,6213 \mathrm{X}$ dengan $\mathrm{R}^{2}=0,26$

\section{B. Saran}

Kayu yang diberi perlakuan awal perendaman dengan larutan $\mathrm{NaOH} 3 \%$ lebih mudah dilengkungkan dibandingkan dengan melulu pengukusan, sehingga cara perlakuan awal ini lebih memudahkan dalam pekerjaan pelengkungan. Namun demikian, perlu ditinjau lebih jauh pengaruh perlakuan $\mathrm{NaOH}$ terhadap penurunan keteguhan kayu.

\section{DAFTAR PUSTAKA}

Anonim.1999. Wood Handbook. Wood as an Engineering Material. Forest Product Laboratory General Technical. Madison. USA.

Bodig J. and B.A.Jayne. 1982. Mechanics of wood and wood composites. Van Nostrand Reinhold Company. New York.

Chugg, W.A. 1964. Glulam. The Theory and Practice of The Manufacture of Glued Laminated Timber Structures. Ernest Benn Limited. London.

Fengel, D. and G. Wegener. 1984. Wood Chemistry, Ultrastucture, Reaction. Walter de Gruyter. Berlin. New York.

Koch, P. tt.a. Utilization of Hardwoods Growing on Southern Pine Sites. Agriculture Handbook No. 605. Vol. II.US Department of Agricultural Forest Service. Oregon.

Kollman, F.P.P. and W.A. Cote. 1968. Principles of Wood Science and Technology, Volume 1. Springer Verlag New York, Inc. New York. 
Malik, J. dan Krisdianto. 2003. Pelunakan kayu mangium dengan uap ammonia untuk pelengkungan kayu. Info Hasil Hutan. Pusat Penelitian dan Pengembangan Teknologi Hasil Hutan. Bogor

Mustafa. 1990. Microstat. Andi Ofset. Yogyakarta.

Natividad, R.A. 1998. Suitability of Acacia mangium for making bendwood for furniture and handicrafts component. Paper presented in The International Conference on Acacia species: wood properties and utilization. Penang.

Rachman, O. dan Saeful. 2001. Sifat pelengkungan 5 jenis kayu dengan cara pengukusan. Fakultas Kehutanan. Universitas Winayamukti. Bandung.

Supriadi, A. dan O. Rachman. 2002. Sifat plengkungan kayu tusam dengan dua macam perlakuan awal. Buletin Penelitian Hasil Hutan 20 (5) : 367-378. Pusat Penelitian dan Pengembangan Teknologi Hasil Hutan. Bogor. 
Lampiran 1A. Hasil uji sidik ragam pelengkungan kayu Appendix 1A. Analysis of variance of wood bending

\begin{tabular}{|c|c|c|c|c|c|}
\hline \multirow{2}{*}{ No. } & \multirow{2}{*}{ Uraian (Decription) } & \multirow{2}{*}{$\begin{array}{l}\mathrm{Db} \\
\mathrm{Df}\end{array}$} & \multicolumn{2}{|c|}{ F tabel (F table) } & \multirow{2}{*}{$\begin{array}{c}\text { F hitung } \\
(F \text { calc. })\end{array}$} \\
\hline & & & $1 \%$ & $5 \%$ & \\
\hline 1 & $\begin{array}{l}\text { Pengaruh praperlakuan terhadap radius } \\
\text { pelengkungan (The effect of pretreatment to } \\
\text { bending radius) }\end{array}$ & 1 & 4,89 & 3,06 & $\left.17,70^{* *}\right)$ \\
\hline 2 & $\begin{array}{l}\text { Pengaruh jenis kayu terhadap radius } \\
\text { pelengkungan (The effect of wood species to } \\
\text { bending radius) }\end{array}$ & 4 & 4,89 & 3,06 & $3,96 *)$ \\
\hline 3 & $\begin{array}{l}\text { Pengaruh kerapatan terhadap radius } \\
\text { pelengkungan (The effect of density to } \\
\text { bending radius) }\end{array}$ & 1 & 8,68 & 4,54 & 4,25 \\
\hline 4 & $\begin{array}{l}\text { Pengaruh pengembangan dimensi terhadap } \\
\text { radius pelengkungan (The effect of swelling to } \\
\text { bending radius) }\end{array}$ & 1 & 8,683 & 4,54 & $\left.9,65^{* *}\right)$ \\
\hline
\end{tabular}

Keterangan (Remarks) : *) Nyata (Significant); **) Sangat nyata (Highly significant)

Lampiran 1B. Hasil uji lanjutan Beda NyataTerkecil pengaruh jenis kayu terhadap radius pelengkungan

Appendix 1B. Analysis Least Significant Different of the effect of wood species to bending radius

\begin{tabular}{|l|l|c|}
\hline No. & \multicolumn{1}{|c|}{ Jenis kayu (Wood species) } & Radius lengkung (Bending radius) \\
\hline 1 & Asam jawa & $22,8 \mathrm{a}$ \\
2 & Marasi & $30 \mathrm{a}$ \\
3 & Balobo & $37,5 \mathrm{a}$ \\
4 & Kendal & $45 \mathrm{a}$ \\
5 & Rasamala & $58,4 \mathrm{~b}$ \\
\hline
\end{tabular}

Keterangan (Remarks) : $\mathrm{a}=$ tidak berbeda nyata (non significant); $\mathrm{b}=$ berbeda nyata (significant) 